\title{
A Novel Route to the Niementowski Reaction
}

\author{
Mazaahir Kidwai,* Shweta Rastogi, Richa Mohan, and Ruby
}

Department of Chemistry, University of Delhi, Delhi-110007, India

RECEIVED JANUARY 31, 2003; RECEIVED JUNE 23, 2003; ACCEPTED JULY 3, 2003

\author{
Key words: \\ Niementowski reaction \\ microwave irradiation (MWI) \\ neat reaction conditions \\ quinazolinone \\ environmentally benign
}

The Niementowski reaction has been extended to synthesize 3-substituted/2,3-disubstituted$4(3 H)$ quinazolinones instead of the 2 -substituted derivatives. The methodology is environmentally benign and completely eliminates the need of solvent from the reaction. Neat reactants were cyclocondensed under microwaves to afford, in good yield, the desired product in less irradiation time as compared to the classical technique. The reaction time was reduced from hours to minutes along with yield enhancement. The rate enhancement and high yield are attributed to the coupling of solvent-free conditions with microwaves.

\section{INTRODUCTION}

The present day industrialization has led to immense environmental deterioration. The coming years, due to strict environmental legislation, entail a challenge for chemists to develop new products and processes that will provide all the benefits of sustainable development. This requires a new approach, which will reduce the material and energy intensity of chemical processes and products, minimize or eliminate the dispersion of harmful chemicals in the environment in a way that enhances the industrially benign approach and meets the challenges of green chemistry. ${ }^{1}$ One of the advances in this area where substantial progress has been made is the microwave-assisted solid-supported synthesis. ${ }^{2}$ In this approach, the reactions are effected by the reagents immobilized on a porous solid support under microwaves. ${ }^{3}$ Careful observation reveals that an appreciable amount of solvent is required for the adsorption of reactants and elution of the product. ${ }^{4}$ The dream of green chemistry has thus come true with the help of the »neat reaction « technology. »Neat reaction« is an alternative solvent-free approach in which a mixture of reactants in the absence of solvent is irradiated under microwaves. The striking features are improved yield, shorter reaction time and easier work-up. This justifies the definition of 'no solvent' because it completely eliminates the need of a solvent. However, adoption of the conventional heating procedures in the absence of solvent may lead to charring.

Quinazolinone derivatives attract a widespread interest due to the diverse biological activities ${ }^{5}$ associated with them. They are pharmaceutically important as antituberculars, ${ }^{6}$ thromboxane $\mathrm{A}_{2}$ synthetase inhibitors, ${ }^{7}$ antibacterials, ${ }^{8}$ antiparkinsons,${ }^{8}$ antihelmintics, ${ }^{9}$ and they also show blood platelet anti-aggregating activity. ${ }^{10}$

Formation of 2-alkyl-4(3H)quinazolinones by condensation of anthranilic acid or substituted anthranilic acid and amides is designated as the Niementowski reac-

* Author to whom correspondence should be addressed. (E-mail: mkidwai@mantraonline.com) 
tion. ${ }^{11}$ This reaction has been found applicable to the amides of lower fatty acids, which show a rapidly decreasing reactivity as molecular weight increases. ${ }^{12} \mathrm{Nu}-$ merous variants of the essential synthesis have been described using acetanthranils and amines, ${ }^{13}$ ammonium $o$-acylaminobenzoates, ${ }^{14} o$-acetaminobenzonitrile in the presence of acetic anhydride ${ }^{15}$ and acyl derivatives of homoanthranilic nitriles and alkaline hydrogen peroxide. ${ }^{16}$ All these reactants are not readily available and some demand synthesis even at the precursor stage. Furthermore, they require expensive reagents, longer reaction times and give unsatisfactory yields. Ziegler, Steiger, and Kappe ${ }^{17}$ also demonstrated the formation of 2-alkyl, 2-aralkyl and 2-aryl-4(3H)quinazolinones in low yield from isatoic anhydride as the source of the anthraniloyl group and the corresponding carboxamide. In the present communication, the Niementowski reaction (Scheme 1) has been extended to the synthesis of 3-substituted-4(3H)quinazolinones in an attempt to improve its yield and applicability.

\section{RESULTS AND DISCUSSION}

The amides or amidines generally used in the Niementowski reaction were replaced by formic acid and primary aromatic or heteroaromatic amines, which<smiles>[R]n1cnc2ccccc2c1=O</smiles>
a $\mathrm{R}=3$-chloro-4-fluorophenyl
b $\mathrm{R}=2$-furfuryl
c $\mathrm{R}=2$-pyridyl
d $\mathrm{R}=$ 2,3-dimethyl-5-oxo-1-phenyl- pyrazol-4-yl

e $\mathrm{R}=5$-phenyl-1,3,4-thiadiazol-2-yl

f $\mathrm{R}=5$-(4-chlorophenyl)-1,3,4-thiadiazol-2-yl

g $\mathrm{R}=5$-methyl-1,3,4-thiadiazol-2-yl

Scheme 1.

TABLE I. Observed yield and reaction time of compounds $\mathbf{2} \mathbf{a}-\mathbf{g}$ and $\mathbf{5 a - g}$

\begin{tabular}{|c|c|c|c|c|c|c|c|c|c|}
\hline \multirow{2}{*}{$\begin{array}{l}\text { Com- } \\
\text { pound }\end{array}$} & \multirow[t]{2}{*}{$\mathrm{R}$} & \multirow[t]{2}{*}{$\mathrm{R}^{\prime}$} & \multirow[t]{2}{*}{ m.p. $/{ }^{\circ} \mathrm{C}^{(\mathrm{a})}$} & \multirow[t]{2}{*}{$T /{ }^{\circ} \mathrm{C}^{(\mathrm{b})}$} & \multicolumn{5}{|c|}{ Microwave irradiation $^{(\mathrm{c})}$ (neat conditions) } \\
\hline & & & & & $t_{1} / \mathrm{min}$ & $p_{1} / \mathrm{w}$ & $t_{2} / \mathrm{min}$ & $p_{2} / \mathrm{w}$ & yield $/ \%$ \\
\hline $2 \mathbf{a}$ & 3-chloro-4-fluorophenyl & - & $100-101$ & 150 & 4.0 & 320 & 2.0 & 560 & 92 \\
\hline $2 b$ & 2-furfuryl & - & $127-128^{(25)}$ & 200 & 4.0 & 320 & 3.5 & 560 & 88 \\
\hline $2 c$ & 2-pyridyl & - & $156-157$ & 220 & 5.0 & 320 & 2.0 & 560 & 90 \\
\hline 2d & $\begin{array}{l}\text { 2,3-dimethyl-5-oxo- } \\
\text { 1-phenylpyrazol-4-yl }\end{array}$ & & 160 & 190 & 3.0 & 320 & 3.0 & 560 & 88 \\
\hline $2 e$ & $\begin{array}{l}\text { 5-phenyl-1,3,4- } \\
\text { thiadiazol-2-yl }\end{array}$ & - & $196-198$ & 220 & 5.0 & 320 & 3.0 & 560 & 89 \\
\hline $2 f$ & $\begin{array}{l}\text { 5-(4'-chlorophenyl)- } \\
\text { 1,3,4-thiadiazol-2-yl }\end{array}$ & - & $298-300^{(26)}$ & 220 & 5.0 & 320 & 3.0 & 560 & 85 \\
\hline $2 \mathrm{~g}$ & $\begin{array}{l}\text { 5-methyl-1,3,4- } \\
\text { thiadiazol-2-yl }\end{array}$ & - & $181^{(26)}$ & 220 & 5.0 & 320 & 2.5 & 560 & 87 \\
\hline $5 \mathbf{a}$ & phenyl & phenyl & $159^{(27)}$ & 230 & 4.0 & 480 & 2.5 & 720 & 88 \\
\hline $5 b$ & phenyl & 2-hydroxyphenyl & 98 & 250 & 4.5 & 480 & 1.5 & 720 & 85 \\
\hline $5 c$ & phenyl & methyl & $147-148^{(28)}$ & 220 & 5.0 & 480 & 1.0 & 720 & 86 \\
\hline $5 d$ & phenyl & octanyl & $52-53$ & 250 & 4.0 & 480 & 1.0 & 720 & 92 \\
\hline $5 e$ & 2-furfuryl & phenyl & $105-107$ & 220 & 3.0 & 480 & 2.5 & 720 & 90 \\
\hline $5 f$ & 2 -furfuryl & 2-hydroxyphenyl & $170-171$ & 220 & 4.0 & 480 & 2.5 & 720 & 90 \\
\hline $5 \mathrm{~g}$ & 2-furfuryl & 3-nicotinyl & $82-83$ & 260 & 3.5 & 480 & 3.0 & 720 & 92 \\
\hline
\end{tabular}

(a) Numbers in brackets are references.

(b) AZ Non-contact IR temperature measurement thermometer.

(c) Microwave irradiations were carried out in a Kenstar microwave oven, model No. OM9925E (2450 MHz, 800 Watts). 


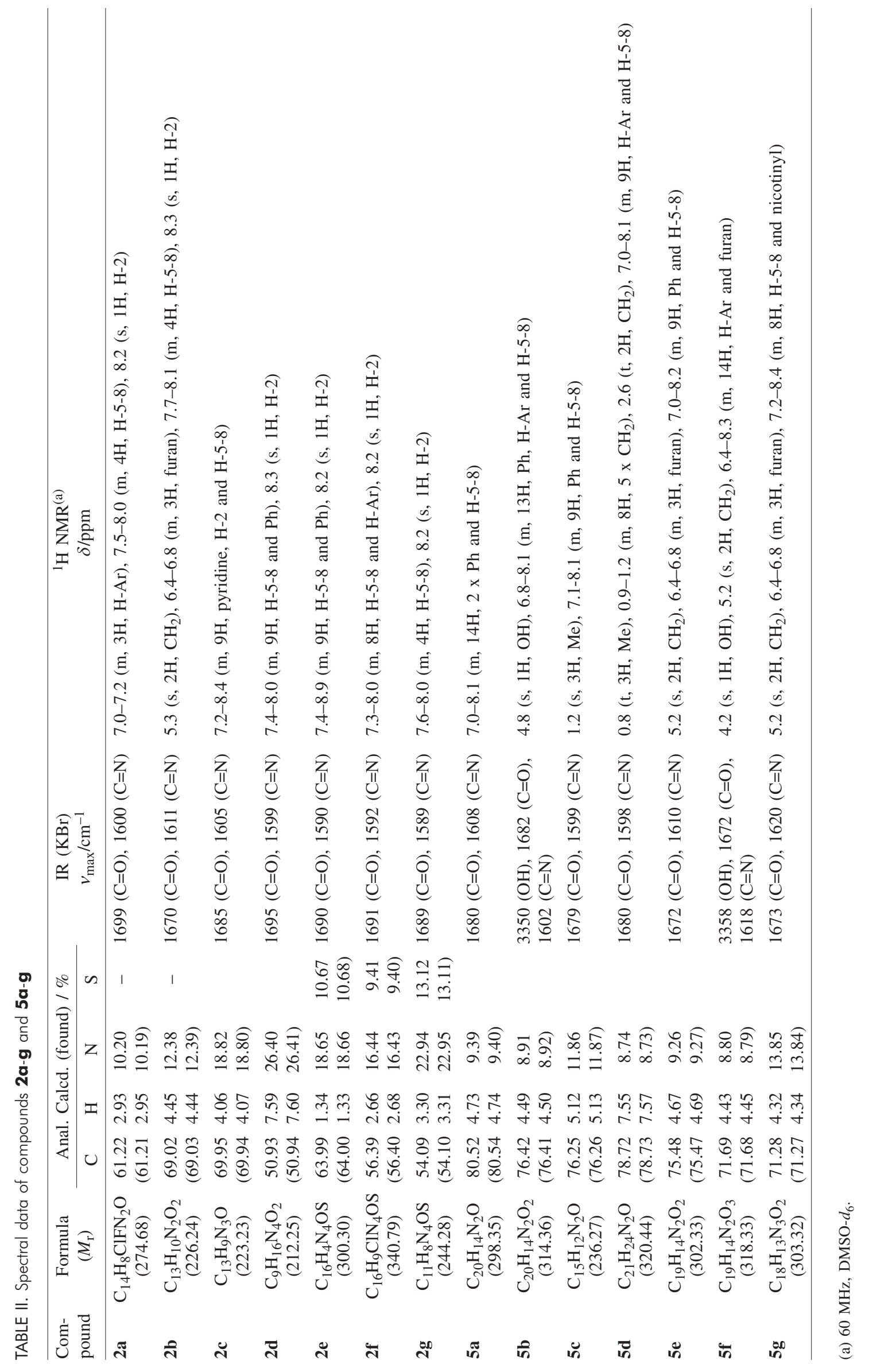




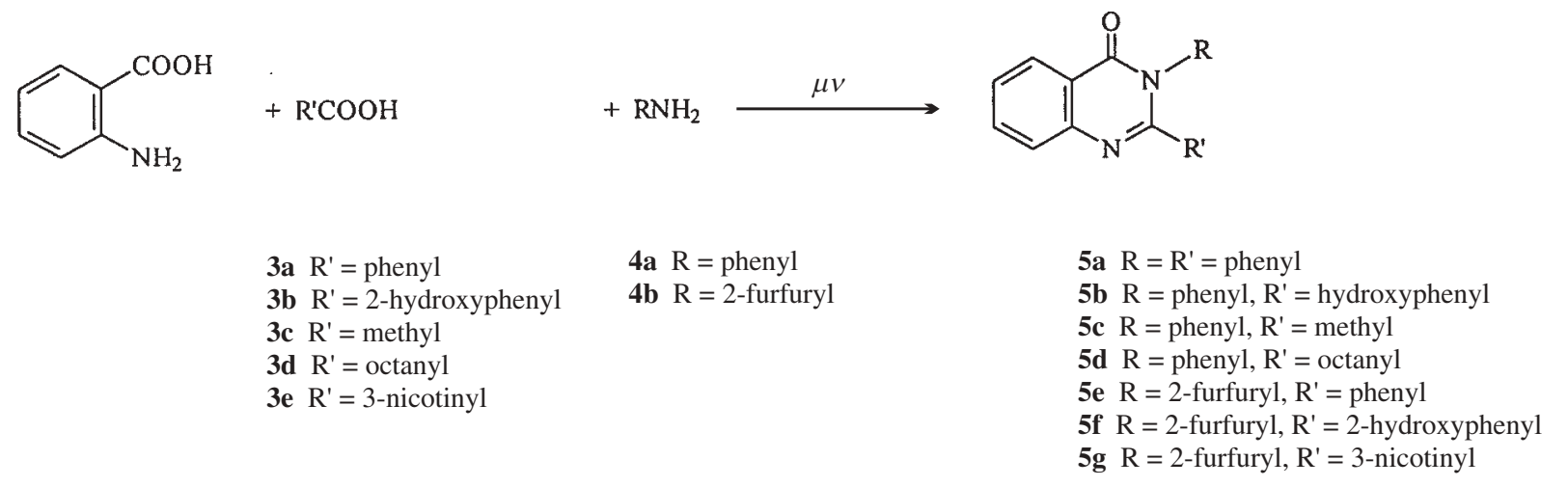

Scheme 2.

afforded 3-substituted-4(3H)quinazolinones instead of the corresponding 2-substituted derivative. We have thus modified the quinazolinone synthesis in which three reactants, anthranilic acid, formic acid and amines, are cyclocondensed. The use of amine and formic acid is beneficial because it offers the advantages of relatively high reactivity in ring closure reactions similar to that involved in the Niementowski reaction. Anthranilic acid and amine (1a-g) when refluxed with an excess of formic acid $(\sim 20 \mathrm{~mL})$ for 4-5 hours usually afforded 3-substituted-4(3H)quinazolinones (2a-g) in moderate yield (Scheme 1). Since no solvent other than formic acid, which itself is one of the reactants, is used in the reaction, it was usually attempted using equimolar amounts of the reactants, including formic acid. This, however, resulted in charring. In continuation of our earlier work on microwave assisted synthesis ${ }^{18}$ and with respect to the advantage of coupling, solvent free conditions ${ }^{19}$ with microwave irradiation (MWI), equimolar amounts of neat reactants were mixed and irradiated under microwaves. ${ }^{20}$ This proved to be a high-yielding protocol (Table I). Thus, an excess of formic acid is not necessary to drive the reaction. This highlights the role of microwaves, attributed to the homogenous heating effects. ${ }^{21}$ The solvent-free quinazolinone synthesis under microwaves proved to be advantageous for environmental reasons. Also, it offers the benefits of shorter reaction times with improved yields, especially when coupled with microwaves (Table I). ${ }^{22}$

Inspired by the high yields obtained using formic acid, a further study of 4(3H)quinazolinones synthesis, as a possible Niementowski reaction, was carried out using different aliphatic, aromatic and heteroaromatic carboxylic acids (Scheme 2). The neat reactants, anthranilic acid, amine (4a-b) and carboxylic acid, (3a-e) were mixed and irradiated under microwaves to yield 2,3-disubstituted-4(3H)quinazolinones $\quad(\mathbf{5 a}-\mathbf{g}) .^{23}$ Good yields were obtained in less irradiation time (Table I) compared to the classical procedure ${ }^{24}$ requiring orthoester, $p$-toluene sulfonic acid and long refluxing. Direct heating of the reactants without solvent com- monly led to charring. It was also observed that the yield of the product increased when higher boiling acids were used, suggesting the optimum temperature for a favorable reaction. The structures of (2a-g) and (5a-g) were confirmed on the basis of spectral and analytical data. IR spectra showed disappearance of bands at 1705-1720 $\mathrm{cm}^{-1}$ to $\mathrm{C}=\mathrm{O}$ of carboxylic group and $3400-3300 \mathrm{~cm}^{-1}$ due to $\mathrm{NH}$ of amine and appearance of the band at $1680-1699 \mathrm{~cm}^{-1}(\mathrm{C}=\mathrm{O})$ and $1580-1610 \mathrm{~cm}^{-1}(\mathrm{C}=\mathrm{N})$. In ${ }^{1} \mathrm{H}$ NMR, disappearance of the signal at $\delta 10.5-12 \mathrm{ppm}$ due to carboxylic proton and a broad signal at $\delta 3-4 \mathrm{ppm}$ due to amine confirmed the formation of products $(\mathbf{2} \mathbf{a}-\mathbf{g})$ and (5a-g) (Table II).

Considering the environmentally friendly role of neat reaction conditions under microwaves, the biopotential of quinazolinones and our ongoing endeavors towards green synthesis, we have thus reported a facile, rapid and environmentally benign quinazolinone synthesis under solvent-free conditions.

\section{REFERENCES}

1. W. Xie, Y. Jin, and P. G. Wang, Chemtech. 29 (1999) 23-29.

2. R. S. Varma, Green Chem. 1 (1999) 43-55.

3. M. Kidwai, R. Venkataramanan, and B. Dave, Synth. Commun. 32 (2002) 2161-2168.

4. D. C. Dittmer, Chem. Ind. (1997) 779.

5. R. K. Satsangi, Indian Drugs 17 (1979) 79-81.

6. V. Joshi and R. P. Chaudhari, Indian J. Chem. 26B (1987) 602-604.

7. W. B. Wright Jr. and A. S. Tomcufcik, U.S. US 4, 684, 654; Chem. Abstr. 107 (1987) 198354.

8. V. K. Srivastava, S. S. Gulati, and K. Shanker, Indian J. Chem. 26B (1987) 652-656.

9. D. P. Gupta, S. Ahmad, A. Kumar, and K. Shanker, Indian J. Chem. 27B (1988) 1060-1062

10. K. Sakai and H. Nahata, Jpn. Kokai Tokkyo Koho JP 63 51, 329; Chem. Abstr. 109 (1988) 86338.

11. V. Niementowski, J. Prakt. Chem. 51 (1895) 564; Beilstein 24143

12. R. Pater, J. Heterocycl. Chem. 8 (1971) 699-702. 
13. M. T. Bogert and V. J. Chambers, J. Am. Chem. Soc. 27 (1905) 649-658.

14. A. Bischler and E. Burkart, Ber. 26 (1893) 1349-1350.

15. M. T. Bogert and A. Hoffman, J. Am. Chem. Soc. 27 (1905) 1293-1301.

16. M. T. Bogert and W. F. Hand, J. Am. Chem. Soc. 24 (1902) 1031-1050.

17. E. Ziegler, W. Steiger, and Th. Kappe, Montash, Chem. 100 (1969) 150-152.

18. M. Kidwai, R. Venkataramanan, and B. Dave, Green Chem. 3 (2001) 278-279.

19. M. Kidwai, S. Saxena, R. Mohan, and R. Venkataramanan, J. Chem. Soc., Perkin Trans. 1 (2002) 1845-1846.

20. A mixture of anthranilic acid $(1.37 \mathrm{~g}, 0.01 \mathrm{~mol})$, amine 1a-g $(0.01 \mathrm{~mol})$ and formic acid $(0.46 \mathrm{~mL}, 0.01 \mathrm{~mol})$ was put into an Erlenmeyer flask. This was subjected to microwave irradiation (MWI). Irradiation was carried out in two stages $\left(t_{1}\right.$ and $\left.t_{2}\right)$ at two different power levels $\left(p_{1}\right.$ and $\left.p_{2}\right)$ (Table I) with a cooling time in-between. The progress of the reaction was monitored by TLC. Upon completion of the reaction, the reaction mixture was worked up with an excess of $10 \% \mathrm{NaHCO}_{3}$ solution and recrystallized from ethanol.
21. D. Stuerga and P. Gaillard, Tetrahedron 52 (1996) 5505-5510.

22. M. Kidwai, P. Sapra, K. R. Bhushan, and P. Misra, Synthesis (2001) 1509-1512.

23. Equimolar amounts of anthranilic acid ( $1.37 \mathrm{~g}, 0.01 \mathrm{~mol})$, amine (4a-b) $(0.01 \mathrm{~mol})$ and carboxylic acid (3a-g) $(0.01$ mol) were put into an Erlenmeyer flask and irradiated under microwaves in two stages $\left(t_{1}\right.$ and $\left.t_{2}\right)$ at two different power levels $\left(p_{1}\right.$ and $\left.p_{2}\right)$ (Table I). Reaction progress was monitored by TLC. Upon completion of the reaction, the reaction mixture was worked up with an excess of $10 \%$ $\mathrm{NaHCO}_{3}$ solution and recrystallized from ethanol.

24. R. W. Leiby, J. Org. Chem. 50 (1985) 2926-2929.

25. D. Gravier, J.-P. Dupin, F. Casadebaig, G. Hou, M. Boisseau, and H. Bernard, Pharmazie 47 (1992) 91-94.

26. S. Giri and H. Singh, J. Indian Chem. Soc. 49 (1972) 175-176.

27. P. A. Petyunin, Y. V. Kozhevnikov, and I. S. Berdinskii, Uch. Zap., Perm. Gos. Univ. 141 (1966) 309; Chem. Abstr. 69 (1968) 77226.

28. L. A. Errede, J. J. McBrady, and H. T. Oien, J. Org. Chem. 42 (1977) 656-658.

\section{SAŽETAK}

\section{Novi pristup Niementowskijevoj reakciji}

\section{Mazaahir Kidwai, Shweta Rastogi, Richa Mohan i Ruby}

Niementowskijeva reakcija je proširena na pripravu 3-supstituiranih/2,3 disupstituiranih-4(3H)kinazolina Priprava je ekološki bezazlena i ne odvija se u otapalu. Čisti reaktanti se ciklokondenziraju pomoću mikrovalova dajući u dobrom iskorištenju željeni produkt izložen u kraćem vremenu zračenju u usporedbi s klasičnom tehnikom priprave. Reakcijsko vrijeme je skraćeno od nekoliko sati na nekoliko minuta, a istovremeno je povećano iskorištenje. 